\title{
Autistic spectrum disorders in Brazilian primary care: Telehealth and face-to-face training method
}

\author{
Rosane Lowenthal ${ }^{1}$ \\ (iD https://orcid.org/0000-0002-6330-850X \\ Luciana C. e Silva ${ }^{2}$ \\ (iD) https://orcid.org/0000-0002-0516-1300 \\ Claudio T. de Miranda ${ }^{3}$ \\ (iD) https://orcid.org/0000-0002-9602-673 \\ Jorge Arthur P. de M. Coelho ${ }^{3}$ \\ iD https://orcid.org/0000-0002-0021-5963 \\ Cristiane S. de Paula² \\ iD https://orcid.org/0000-0003-0438-9407
}

To cite this paper: Lowenthal, R., Silva, L. C., Miranda, C. T., Coelho, J. A. P. M., \& Paula, C. S. (2019). Autistic spectrum disorders in Brazilian primary care: Telehealth and face-to-face training method. Psicologia: Teoria e Prática, 21(3), 501-516. doi:10.5935/19806906/psicologia.v21n3p501-516

Submission: 02/04/2019

Acceptance: $12 / 06 / 2019$

1 Faculty of Medical Sciences of Santa Casa de São Paulo (FCMSCSP), São Paulo, SP, Brazil.

2 Mackenzie Presbyterian University (UPM), São Paulo, SP, Brazil.

3 Federal University of Alagoas (Ufal), Maceió, AL, Brazil. 


\begin{abstract}
Primary care professionals are usually the first ones to detect symptomns of autism. We have developed and evaluated an educational model via a combined telehealth and face-to-face approach to handle autism spectrum disorders (ASD) and child mental health. The training comprised two modules involving distance-learning and face-to-face teaching environments. A total of 150 healthcare professionals -75 doctors and 75 nurses - from five Brazilian cities were trained. Videos about ASD and child mental health were developed for the distance-learning module. The face-toface module was based on training regarding "Mental health communication skills for child and adolescent primary care." The professionals were evaluated before and after training utilizing a specific knowledge questionnaire and surveys on Knowledge, Attitude, and Practice (KAP). Knowledge acquisition, practice, and attitude improved significantly after training $(p<0.01)$. Our results indicated that the use of interactive tele-education to train professionals in primary care is feasible and effective.
\end{abstract}

Keywords: autistic disorder; primary health care; physicians; nurses; training.

\title{
TREINAMENTO SOBRE TRANSTORNO DO ESPECTRO AUTISTA NA ATENÇÃO BÁSICA DO BRASIL: TELEDUCAÇẤO E PRESENCIAL
}

\begin{abstract}
Resumo
Os primeiros sintomas de transtorno do espectro autista (TEA) são detectados por profissionais da atenção básica. O objetivo deste estudo foi desenvolver e avaliar um modelo de treinamento via telemedicina e workshop presencial sobre TEA e saúde mental infantil para médicos e enfermeiros da atenção básica. Participaram do treinamento 150 profissionais de cinco cidades brasileiras. No módulo a distância, foram desenvolvidos vídeos sobre TEA e os principais transtornos da infância, e no presencial foi baseado no treinamento "Técnicas de comunicação para lidar com saúde mental de crianças e adolescentes na atenção primaria". Os profissionais foram avaliados antes e depois da capacitação com questionários específicos de conhecimento e o Questionário de conhecimento, atitudes e prática (CAP). Os resultados apontaram a aquisição de conhecimento, atitudes e prática tanto pelos médicos quanto pelos enfermeiros. Os resultados deste estudo mostram que o treinamento de profissionais da atenção básica é factível e efetiva.

Palavras-chave: transtorno autístico; atenção básica; medicos; enfermeiros; capacitação.
\end{abstract}




\title{
ENTRENAMIENTO EN TRANSTORNO DEL ESPECTRO AUTISTA EN LA ATENCIÓN BÁSICA BRASILEÑA: TELEDUCACIÓN Y PRESENCIAL
}

\begin{abstract}
Resumen
Los profesionales que detectan los primeros síntomas de trastorno del espectro autista son los profesionales de la atención básica. Desarrollamos y evaluamos un modelo de educación vía tele-salude y taller presencial sobre TEA y salud mental infantil para médicos y enfermeros de la atención básica. 150 profesionales de 5 ciudades brasileñas participaron en el entrenamiento. Para el módulo a distancia se desarroIlaron vídeos sobre TEA y los principales trastornos de la infancia. El módulo presencial se basó en el entrenamiento "Técnicas de comunicación para lidiar con la salud mental de niños y adolescentes en la atención primaria". Los profesionales fueron evaluados antes y después de la capacitación con Cuestionario Específicos de Conocimiento y el Cuestionario de conocimiento, actitudes, práctica (CAP). Los resultados apuntaron que hubo adquisición de conocimiento, actitud y práctica tanto por los médicos y por los enfermeros. Los resultados muestran que el uso de tele-educación interactiva para la capacitación es factible y efectiva.

Palabras clave: trastorno autista; atención primaria de salud; médicos; enfermeros; capacitación.
\end{abstract}

\section{Introduction}

Low detection of mental disorders in children and lack of qualified healthcare professionals are the main barriers to implementing effective mental health treatment worldwide (Perou et al., 2013). These barriers also include people with autism spectrum disorders (ASD). Although international guidelines recommended screening for ASD at 18 and 24 months of age over ten years ago, ASD is detected much later in most children, which negatively impacts treatment and prognosis (Zwaigenbaum et al., 2015).

ASD imply neurodevelopmental disorder, and the onset of symptoms occurs in the early years of childhood. If not treated early, ASD may impair the individual's functionality. In most countries, including Brazil, the first professionals that can potentially detect some developmental deficits are those working in primary care units (Bordini et al., 2015).

An estimated $0.6 \%-1.5 \%$ of the world population has ASD (Elsabbagh et al., 2012). Given this increasing prevalence, it is highly probable that primary care pro- 
fessionals (especially pediatricians) will come across children with ASD, many of whom without a previous diagnosis. Therefore, primary care professionals have to be knowledgeable about the red flags of the risk of ASD, so that they can assist children with ASD and their families in their needs. However, primary care professionals often report a lack of training in symptoms recognition and medical management of children with ASD (Bellando \& Fussell, 2015).

On the other hand, parents of children with ASD report that primary care professionals are usually concerned about their children's physical health and rarely address developmental issues (Biel, Anthony, Mlynarski, Godoy, \& Beers, 2017). A study carried out in the Brazilian public healthcare system showed that mothers of children with ASD began to notice developmental disturbances around 24 months of age on average, whereas their children were diagnosed with ASD only three years later (Ribeiro, Paula, Bordini, Mari, \& Caetano, 2017).

The Brazilian healthcare system was organized after the Constitution of 1988 was promulgated. This Constitution declared that health was a civil right and that it was the duty of the State to provide health services. Since 1994, the Primary Care System in Brazil has consisted of Primary Care Centers (acronym in Portuguese: UBS), which have the primary mission of promoting alternative community-centered treatment models and are staffed by Family Health Strategy multidisciplinary teams (Paula, Lauridsen-Ribeiro, Wissow, Bordin, \& Evans-Lacko, 2012). To meet the patient's needs, including child mental healthcare, this model requires better qualified primary care professionals. An increasing number of young patients are being assisted at primary care units, but care provision is still limited (Fatori, Evans-Lacko, Bordin, \& Paula, 2012; Paula, Duarte, \& Bordini, 2007), and primary care professionals have been trained particularly through telehealth all over the country (Wen, 2006).

In Brazil, laws number 8080/90 and 8142/90 issued in 1990 regulate the Unified Health System (acronym in Portuguese: SUS). The System is based on universality, equity, integrality, decentralization, hierarchization, regionalization, and community participation. Regarding regionalization and hierarchization, health services must be divided based on complexity, and each service must have a specific area of action and target a specific audience. Access to services should be sequenced from the primary level and follow the hierarchy of attention levels according to what is necessary to solve the problem (Brasil, 1990). 
After the System was implemented, Primary Care emerged as a fundamental strategy for this new organization of the national public healthcare system and is considered the preferential gateway of the healthcare process (Paula, Nakamura, Wissow, Bordin, \& Nascimento, 2009). In this structure, Primary Care should provide aid, including health prevention, promotion, and treatment. Consequently, this model requires that primary care professionals be better qualified to know patients' needs, including mental, emotional, and behavioral health problems in children and adolescents, especially in the case of ASD. The emphasis placed on ASD is due to its high prevalence rates, not to mention that it is the most severe disorder with chronic symptoms and deficits in adaptive functioning (Lowenthal, 2014).

In the last ten years, studies have shown that telehealth can offer an innovative distance strategy to provide the population with effective and efficient access to healthcare professionals. In this sense, Telemedicine has also been considered an interesting tool to disseminate knowledge, especially if we consider that the decreasing costs of most communication technologies can contribute to integrating healthcare professionals by overcoming the geographical seclusion issue (Wen, 2006). This instrument is particularly significant in Brazil, which is a large country with a diverse socioeconomic population and heterogeneous regional healthcare infrastructure distribution. The Brazilian government recognized the importance of tele-education in healthcare in a national document dated of 2011.

In developed countries, Telemedicine has been primarily used to access vulnerable families or people living in rural areas. In the particular case of the ASD population, research has been focused on providing telephone-based and telepsychiatry consultation in primary care (Hepburn, Blakeley-Smith, Wolff, \& Reaven, 2016; Mazurek, Brown, Curran, \& Sohl, 2016).

To the best of our knowledge, in Brazil, there are three publications that focus on training public health professionals in ASD. In one of such studies, 22 primary care professionals participated in five three-hour weekly training sessions that involved lectures and discussion of ASD cases concerning topics such as epidemiology, early signs, evidence-based therapies, and SUS structuring. In this case, ASD identification was the target subject, and the participants were assessed before and after training. To measure knowledge acquisition, the researchers developed a structured questionnaire comprising 13 multiple-choice questions and vi- 
gnettes of clinical ASD cases. At the end of the training, the level of knowledge of the trained professionals had improved by $81.8 \%$ (mean score, 6.73 vs. $9.18, p=$ 0.01). Four months later, the number of patients with ASD forwarded to specialized service had increased (Bordini et al., 2015).

Another model consisted of training the staff of four Sao Paulo psychosocial care centers for children and adolescents (CAPSi). The program encompassed six phases: 1. pre-intervention observation; 2. meeting with participants to assess the main needs of the training program; 3 . developmental training and design of assessment materials; 4 . additional meeting to discuss the training program implementation; 5. final meeting for case discussion and evaluation; and 6. distance supervision. Professionals from multiple areas enrolled for the training. All the discussions and evaluations of this training were based on videos featuring children and adolescents with ASD in different situations. The results showed that the KAP questionnaire increased in two domains, Knowledge $(p=0.003)$ and Attitude $(p=0.05)$, but not in Practice $(p=0.186)$ (Silva, Paula, Teixeira, \& Lauridsen-Ribeiro, 2016).

Another study sought to assess a four-month training course that was offered to Community Health Agents (CHAs). The results showed that the course was effective: knowledge and satisfaction increased. This program is important in Brazil because CHAs are the first level of a family's access to primary healthcare. Furthermore, considering that the program requires CHAs to pay monthly visits to the homes of infants up to the age of 24 months, they are allowed to assess such infants in their natural environments and to detect developmental deviations (Lampert, 2018).

Considering the lack of Brazilian research on the improvement of care delivered to children with ASD, particularly in the context of the primary care system, this study aimed to develop and to evaluate an education model via telehealth and face-to-face workshop on ASD and child mental health offered to health professionals working in Primary Care Centers.

\section{Method}

After approval by the institutional Research Ethics Committee, a training program on ASD and childhood mental health was offered to primary care professionals from October 2012 to October 2013. 


\subsection{Site and sample}

A quasi-experimental study design was conducted in five cities selected from three regions of Brazil: São Paulo (São Paulo), Caeté (Minas Gerais), Fortaleza (Ceara), Recife (Pernambuco), and Goiânia (Goias). The researchers contacted the local Health Secretariats of each city and asked them to indicate 30 professionals to participate in the study. The cities were chosen for convenience. Thus, the sample consisted of 150 professionals ( 75 family practice physicians and 75 nurses) working in the Family Health Strategy program in these five cities. All the 150 professionals completed the online training program, but ten physicians and five nurses did not take part in the face-to-face module for schedule reasons.

\subsection{Study phases}

The training was implemented in two modules: a telehealth (distance) module and a face-to-face module. For the distance module, an Interactive Learning platform was developed to allow participants to access the content videos and a discussion list and to fill in the evaluation questionnaires. An electronic tutor managed the Interactive Learning platform and controlled the scientific content, level of participation, and performance.

Because these primary care professionals did not have specific training in child mental health, the first step was to teach them how to identify the most prevalent mental health disorders and ASD (one of the most severe disorders) via a series of videos. The one-month distance module presented five videos lasting an average of 10 minutes to the participants. The researchers had previously designed the videos and, during the watching period, discussion lists were used. All the videos followed the same format and showed 1. the difference between normal and pathological behavior; 2 . the main symptoms of each disorder based on ICD-10 and DSM-IV; and 3. a guide on healthcare procedures and behaviors. Each video was developed based on expert advice about each disorder. When the primary care professionals accessed the video platform for the first time, they were already granted access to all the material. The videos remained available until one month after the end of the face-to-face training module.

The 12-hour face-to-face module was conducted two weeks after the end of the distance module. This phase comprised an intensive one-day-and-a-half workshop held in each city and included a series of interactive training and locally 
relevant content that were structured around theory and practice. This module was based on the Brazilian version of a model entitled: "Mental health communication skills for child and adolescent primary care" developed by Dr. Lawrence Wissow from Johns Hopkins University (Lowenthal, 2014). This training phase consisted mainly of active methodologies with simple and inexpensive audiovisual resources, such as PowerPoint slides, video presentations, and role-plays. The main goals were a) to reduce the primary care professionals' feeling of lack of competence, b) to reduce the primary care professionals' fears of "making matters worse", c) to demonstrate the importance of taking interest in psychosocial topics, and d) to address barriers concerning the treatment of mental health problems. Difficulties in diagnosing ASD and training in screening questionnaires like the Autism Behavior Questionnaire and the Modified Checklist for Autism in Toddlers were also addressed.

\subsection{Instruments}

To assess the impact of the intervention model, two structured instruments were used. First, a Specific Knowledge Questionnaire (SKQ) that the authors created specifically for this study was applied. The SKQ consisted of a multiple-choice test comprising 15 questions that helped to assess the primary care professionals' level of knowledge before and after the distance module; each question had one possible correct answer. Then, a questionnaire containing 20 questions about Knowledge, Attitude, and Practice (KAP) was employed to assess the attitude, practice, and knowledge levels related to the evaluation and management of ASD and child mental health disorders. Each question could be answered with a response that ranged from o to 9 on a Likert scale.

The primary care professionals answered the two questionnaires (SKQ and KAP) at the beginning of the distance module. The SKQ and the KAP were answered again at the end of the distance module and of the face-to-face module, respectively.

Also, at the end of the training program, the participants filled out a training program evaluation form about the e-learning material, the speakers, the workshop material, and the whole content. More specifically, the evaluation form contained 12 questions about the participants' opinions of various aspects of the training, including the training dynamics and format, the methodology used during the 
distance and face-to-face modules, the didactic material, and the interaction between the participants and the coordination team.

\subsection{Statistical Analysis}

Data analysis was used to compare each participant's initial and final performances by a paired t-test. When the scores were assessed between groups with time effects, the General Linear Model test was employed. All the data were submitted to the Kolmogorov-Smirnov test to evaluate normality. The level of significance was set at $5 \%$.

\section{Results}

The mean age of the 150 trained professionals was 36.8 years (SD 7.6). Most of them ( $89 \%$ ) were aged 30-39 years; 17 (12.6\%) were aged $40-49$ years and 18 $(13.3 \%)$ were aged above 50 . Most of the participants were female (87, 64.5\%), and $1 / 3$ of them (44 participants) specialized in family healthcare.

Regarding the SKQ questionnaire, the mean score improved significantly from 5.9 (SD 0.93) before 6.80 (SD 1.04) after training ( $<<0.01$ ) (Table 3.1).

Table 3.1. Comparison of the difference between the means of adjustment for SKQ before and after training.

\begin{tabular}{ccccccc}
\hline $\begin{array}{c}\text { Knowledge } \\
\text { Questionnaire }\end{array}$ & Mean & Media & SD & Minimum & Maximum & N \\
\hline Before & 5.9 & 5.78 & 0.93 & 4.34 & 7.89 & 150 \\
\hline After & 6.8 & 6.75 & 1.04 & 4.64 & 8.76 & 150 \\
\hline Difference & $0.9^{*}$ & & 1.03 & 4.64 & 8.76 & \\
\hline
\end{tabular}

$\mathrm{SD}=$ standard deviation.

$* p<0.01$ Descriptive level of Student's t-test for paired samples.

When we split the professionals into the categories doctors and nurses, knowledge improved in both categories $(p<0.01)$, and there was no interaction between them $(p=0.16)$ (Table 3.2). 
Table 3.2. Comparison of the difference between the means of adjustment for the SKQ before and after training, divided into professional categories.

\begin{tabular}{ccccccc}
\hline & \multicolumn{3}{c}{ Doctors $(\mathrm{N}=70)$} & \multicolumn{3}{c}{ Nurses $(\mathrm{N}=70)$} \\
\hline $\begin{array}{c}\text { Knowledge } \\
\text { Questionnaire }\end{array}$ & Before & After & Difference & Before & After & Difference \\
\hline Mean & 6.32 & 7.31 & $0.99^{*}$ & 5.77 & 6.13 & $0.36^{*}$ \\
\hline SD & 0.92 & 0.90 & 0.60 & 0.92 & 0.78 & 1.32 \\
\hline
\end{tabular}

Condition of equality of variance and covariance matrixes between groups - verified by Box test $*_{p}=0.38$. Kolmogorov-Smirnov test for normality before $p=0.66$ and after $p=0.60$.

Table 3.3 describes results of the KAP questionnaire (Knowledge, Attitude, and Practice). Considering the total score of the KAP, there was an improvement of 21.59 points, from $95.24(S D=14.13)$ before training to $116.83(S D=17.41)$ after training $(p<0.01)$. The same pattern was observed for the mean Attitude and Practice levels.

Table 3.3. Comparison of the difference between the means of adjustment for the knowledge attitude and practice questionnaires before and after training, divided into professional categories

\begin{tabular}{lccc}
\hline \multicolumn{1}{c}{ KAP } & Before & After & Difference \\
\hline Total & & & $21.59^{*}$ \\
\hline Mean & 95.24 & 116.83 & \\
\hline Median & 97.0 & 118.0 & 14.81 \\
\hline SD & 14.13 & 17.41 & $7.96^{*}$ \\
\hline Knowledge & & & 6.49 \\
\hline Mean & 20.09 & 28.05 & \\
\hline Median & 20.0 & 27.0 & $8.21^{*}$ \\
\hline SD & 4.75 & 4.11 & 8.20 \\
\hline Attitudes & & & \\
\hline Mean & 18.20 & 26.41 & $6.59^{*}$ \\
\hline Median & 16.0 & 27.0 & 10.32 \\
\hline SD & 6.65 & 7.66 & \\
\hline Practice & & 63.82 & \\
\hline Mean & 57.23 & 67.0 & \\
\hline Median & 61.0 & 10.79 & \\
\hline SD & 10.77 & & \\
\hline
\end{tabular}

$* p<0.01$ Descriptive level of Student's t-test for paired samples. 
Analysis of the differences in KAP, according to the professional category before and after training, showed that doctors had a higher total KAP, Attitude and Practice mean levels, as compared to nurses before training. After training, all the KAP categories increased similarly over time without significant interaction between group and time. On the other hand, the specific subscale of knowledge was similar between physicians and nurses before training, while the increase remained similar between the two groups, with no significant difference in relation to time $(p=0.33)$ nor interaction between groups $(p=0.82)$ after training (Table 3.4 ).

Table 3.4. Comparison of the difference between the means of adjustment for the KAP.

\begin{tabular}{|c|c|c|c|c|c|c|}
\hline \multicolumn{7}{|c|}{ Questionnaires before and after training, divided into professional categories } \\
\hline \multicolumn{3}{|c|}{ Doctors $(\mathrm{N}=65)$} & \multicolumn{4}{|c|}{ Nurses $(\mathrm{N}=70)$} \\
\hline KAP & Before & After & Difference & Before & After & Difference \\
\hline \multicolumn{7}{|l|}{ Total } \\
\hline Mean & 95.24 & 116.83 & 21.59 & 89.73 & 108.64 & 18.91 \\
\hline SD & 11.5 & 10.8 & 10.4 & 11.7 & 18.2 & 17.8 \\
\hline \multicolumn{7}{|c|}{ Knowledge } \\
\hline Mean & 23.82 & 33.4 & 9.58 & 22.81 & 29.65 & 6.84 \\
\hline SD & 4.52 & 4.08 & 5.98 & 4.53 & 4.07 & 5.67 \\
\hline \multicolumn{7}{|l|}{ Attitudes } \\
\hline Mean & 18.85 & 28.32 & 9.47 & 12.62 & 22.89 & 10.27 \\
\hline SD & 4.72 & 4.58 & 5.32 & 5.79 & 9.9 & 10.01 \\
\hline \multicolumn{7}{|l|}{ Practice } \\
\hline Mean & 60.5 & 64.3 & 3.8 & 54.3 & 56.1 & 11.8 \\
\hline SD & 10.9 & 7.25 & 8.31 & 8.57 & 10.54 & 11.29 \\
\hline
\end{tabular}

As mentioned above, the KAP questionnaire had 15 items. We analyzed the three single items related to ASD in this questionnaire: one item about ASD symptoms, one item about proper ASD age of diagnosis, and one item about the participant's attitude to establishing a differential diagnosis in ASD. All the three items improved significantly after the intervention program ( $p=0.02, p=0.01$, and $p=0.03$, respectively).

Finally, acceptance of the training program was high: i) 117 primary care professionals (86.6\%) classified it as excellent, ii) only 12 primary care professionals $(8.8 \%)$ considered that it was too difficult, and iii) 119 primary care professionals $(88.3 \%)$ evaluated the training program duration as satisfactory. Also, all the prima- 
ry care professionals approved the e-learning model and would recommend it to other professionals.

\section{Discussion}

This study aimed to develop and to evaluate a training model for primary care professionals. The results show that the training implemented in the current study improves professionals' knowledge, attitude, and practice about ASD and other children mental health disorders in the primary care setting.

When all the 150 participants are considered, their overall knowledge level is significantly higher at the end of the training program. This improvement can also be noticed when doctors and nurses are evaluated separately. A previous study has demonstrated that online learning is a desirable, efficient, and cost-effective way to provide continuing education to professionals. In the mental health field, online programs have proven effective in training clinicians to identify and to assess depression and schizophrenia symptoms (Kobak et al., 2010). Therefore, the results of the present study, which are based on an innovative methodology that uses distance modules with multimedia material, are particularly promising in the field of ASD and covers different ways of learning.

An example of online programs for ASD is an American study employing the ECHO model, which has already been shown to be efficient for other diseases. Through this model, secure videoconferencing technology connects primary care providers to a team of specialists at an academic medical center. In turn, the specialists provide education in best-practice treatment protocols, case-based learning, and co-management. During the six-month pilot project, two-hour clinics were conducted twice every month. The expert panel, which consisted of healthcare professionals (including ten pediatricians) and the parent of a child with ASD, was located at an academic medical center. At the end of the ECHO model, the use of autism-specific resources increased significantly from pretest to post-test among all participants. Besides, the percentage of pediatricians in full compliance with the guidelines for ASD screening rose from 30\% to 60\% from pre- to post-test (Mazurek et al., 2016).

In South Africa, a group of researchers tested a program called AutismNavigator ${ }^{\circledR}$ for Primary Care. This program is a web-based course that was designed to increase awareness of the ASD red flags in order to promote earlier detection and referral for intervention. The program contains extensive video illustrations that 
offer rapid access to multiple exemplars of ASD red flags (Chambers, Vries, Delehanty, \& Wetherby, 2018).

In the present study, we also verified that the level of attitude and practice toward ASD and another child mental health diagnosis augments and after the training program in the whole group, as well as in the separate categories (i.e., doctors and nurses). In the USA, a study focusing on communication skills was conducted with primary care pediatricians. The study demonstrated improved parental symptoms and reduced minor impairment associated with mental health problems in the children (Wissow et al., 2008).

The difference between the change in attitude and practice levels among professionals before and after training is more pronounced for the attitude level, which suggests that the professionals change their thoughts and viewpoint about ASD and other child mental health disorders, but they do not have enough time to implement the new knowledge during clinical practice. Regarding the essence of the educational process, training should particularly consider the possibility of an effective change in the behavior of healthcare professionals. We know that modifying clinical practice requires that attitudes are changed and knowledge is acquired. Therefore, future studies should include a follow-up evaluation to measure how the intervention program impacts primary care professionals' daily activities in the long term.

The best measure when it comes to practice effectiveness is to check for a certain period whether trained professionals can identify infants with ASD signals and refer them to specialized care. Our study has not been able to measure this, but the study with pediatricians showed that symptoms identification improved, and that six times as many suspected cases were referred to a specialized mental health service as compared to the previous four months (Bordini, 2015), resembling the data from the study involving CHAs (Lampert, 2018).

Another study involving 14 professionals (four nursing assistants, three nurses, two speech therapists, an occupational therapist, a pharmacy technician, a support worker, a psychopedagogist, and a nutritionist) from four Psychosocial Care Centers for Children and Adolescents (CAPSi) from the Northern Regional Health Coordination Body of the city of São Paulo city was recently conducted. A face-to-face training program that used videos and questions to assess knowledge about signs/symptoms and intervention techniques to support children with ASD was offered together with the KAP questionnaire. The results were also promising: 
they revealed that the participants' knowledge and attitudes increased significantly. There was also a rise in the percentage of correct answers for 11 of the 13 videos employed during evaluation. As for participants' satisfaction, all of them had a positive reaction to the training: $100 \%$ of the assessments related to i) course organization; ii) teaching; iii) themes; and iv) training duration received a score of excellent (52\%) or good (48\%) (Silva et al., 2016).

The current study has some limitations, such as the lack of a follow-up phase after the training program. Therefore, results are limited to the impact of the program on primary care immediately after training. Data on maintenance are missing, but they would be particularly important to verify whether the practice component improves in the long term. Another limitation is that the study we performed in five different places, located in distinct regions of Brazil, but there was no control group.

Finally, the training described here is brief; there is no continuity or further participants' monitoring. Nevertheless, the proposal is feasible and inexpensive, meeting the needs for training on a large scale. To improve this proposal, we believe it is essential to design a virtual support network providing support questions, case discussion, and even updated the information to participants after the training period, thereby transforming a brief training program into continuing education.

In conclusion, our results indicate that the use of interactive tele-education to train primary care professionals is feasible, well-accepted, and effective.

\section{References}

Bellando, J., \& Fussell, J. J. (2015). Autism speaks toolkits : Resources for busy physicians. Clinical Pediatrics, 55(2), 171-175. doi:10.1177/0009922815594587

Biel, M. G., Anthony, B. J., Mlynarski, L., Godoy, L., \& Beers, L. S. (2017). Collaborative training efforts with pediatric providers in addressing mental health problems in primary care. Academic Psychiatry, 41(5), 610-616. doi:10.1007/s40596-017-0709-1

Bordini, D., Lowenthal, R., Gadelha, A., Araujo, G. M. Filho, Mari, J. D. J., \& Paula, C. S. (2015). Impact of training in autism for primary care providers: A pilot study. Revista Brasileira de Psiquiatria (Sao Paulo, Brazil: 1999), 37(1), 63-66. doi:10.1590/ 1516-4446-2014-1367

Brasil. Lei no 8.080 de 19 de setembro de 1990. Sistema Único de Saúde. Diário Oficial da União, Brasília, DF. 20 de Setembro de 1990. Retrieved from http://conselho.saude. gov.br/legislacao/index.htm 
Chambers, N. J., Vries, P. J. de, Delehanty, A. D., \& Wetherby, A. M. (2018). Feasibility of Utilizing Autism Navigator ${ }^{\circledR}$ for Primary Care in South Africa, 11, 1511-1521. doi:10.1002/aur.2018

Elsabbagh, M., Divan, G., Koh, Y. J., Kim, Y. S., Kauchalli, S., Marcín, C., ... Fombonne, E. (2012). Global prevalence of autism and others pervasive developmental disorders. Autism Research, 5(3),160-179. doi:10.1002/aur.239

Fatori, D., Evans-Lacko, S., Bordin, I. A., \& Paula, C. de. (2012). Correspondence Ways out of the crisis behind Bribegate for Child mental health care. The Lancet, 379(9812), e16-e17. doi:10.1016/S0140-6736(12)60105-6

Hepburn, S. L., Blakeley-Smith, A., Wolff, B., \& Reaven, J. A. (2016). Telehealth delivery of cognitive-behavioral intervention to youth with autism spectrum disorder and anxiety: A pilot study, 20(2), 207-218. doi:10.1177/1362361315575164

Kobak, K. A., Leuchter, A., DeBrota, D., Engelhardt, N., Williams, J. B., Cook, I. A., ... Alpert, J. (2010). Site versus centralized raters in a clinical depression trial: Impact on patient selection and placebo response. Journal of Clinical Psychopharmacology, 30(2),193-197. doi:10.1097/JCP.obo13e3181d20912

Lampert, S. S., Lamoglia, A., \& Bosa, C. A. (2018). The Importance of evaluating training programs aimed at the identification of early markers of Autism Spectrum Disorder (ASD). Temas em Psicologia, 26, 1411-1425.

Lowenthal, R. (2014). Capacitação em Saúde Mental na Infância e na Adolescência para Profissionais da Atenção Primária. São Paulo: Editora Meckenzie.

Mazurek, M. O., Brown, R., Curran, A., \& Sohl, K. (2016). ECHO Autism : A new model for training primary care providers in best-practice care for children with autism. Clinical Pediatrics, 56(3), 247-256. doi:10.1177/0009922816648288

Paula, C. S. de, Duarte, C., \& Bordini, I. (2007). Prevalence of mental health problems in children and adolescents from the outs-kirts of São Paulo City and estimation of services need and capacity. Revista Brasileira de Psiquiatria, 29, 11-27. doi:10.1590/ S1516-44462006005000012

Paula, C. S., Lauridsen-Ribeiro, E., Wissow, L., Bordin, I. A. S., \& Evans-Lacko, S. (2012). How to improve the mental health care of children and adolescents in Brazil: actions needed in the public sector. Revista Brasileira de Psiquiatria (São Paulo, Brazil: 1999), 34(3), 334-351. doi:10.1016/j.rbp.2012.04.001

Paula, C. S., Nakamura, E., Wissow, L., Bordin, I. A., \& Nascimento, R. (2009). Primary care and children's mental health in Brazil. Mental Health and Child Development, 9(4), 249-255. doi:10.1016/j.acap.2009.02.006 
Perou, R., Bitsko, R., Blumberg, S. J., Pastor, P., Ghandour, R. M., \& Gfroerer, J. C. (2013). Mental health surveillance among children - United States, 2005-2011. MMWR Supplement, 17, 1-35.

Ribeiro, S. H., Paula, C. S. de, Bordini, D., Mari, J. J., \& Caetano, S. C. (2017). Barriers to early identification of autism in Brazil. Revista Brasileira de Psiquiatria, 39, 352-354. doi:10.1590/1516-4446-2016-2141

Silva, L. C., Paula, C. S. D., Teixeira, M. C. T. V., \& Lauridsen-Ribeiro, E. (2016). Impact of training program to treat children with autism in CAPSi units. Revista Brasileira de Psiquiatria, 40(3), 296-305. doi:10.1590/1516-4446-2016-2090

Wen, C. L. (2006). Telemedicina e Telessaúde - um panorama no Brasil. Atual Bras Telemed Telessaúde, 2, 3-5.

Wissow, L., Gadomski, A., Roter, D., Larson, S., Brown, J., Zachary, C., ... Wang, M.-C. (2008). Improving child and parent mental health in primary care: A cluster-randomized trial of communication skills training. Pediatrics, 121(2), 266-75. doi:10.1542/peds.2007-0418.

Zwaigenbaun, L., Bauman, M. L., Stone, W. L., Yirmiya, N., Estes, A., Hansen, R. L., ... Wetherby, A. (2015). Early identification of Autism Spectrum Disorder: Recommendations for practice and research. Pediatrics, 136(1), S60-S81. doi:10.1542/ peds.2014-33667E

\section{Authors notes}

Rosane Lowenthal, Health Sciences Postgraduate Program, Santa Casa de São Paulo School of Medical Sciences; Luciana C. e Silva, Development Disorder Postgraduate Program, Mackenzie Presbyterian University (UPM); Claudio T. de Miranda, Health Sciences Postgraduate Program, University of Alagoas (Ufal); Jorge Arthur P. de M. Coelho, Computational Knowledge Modeling Postgraduate Program, University of Alagoas (Ufal); Cristiane S. de Paula, Development Disorder Postgraduate Program, Mackenzie Presbyterian University (UPM).

Correspondence concerning this article should be addressed to Rosane Lowenthal, Rua Turiassú, 390, cj. 72, São Paulo, SP, Brazil. CEP 05005-000.

E-mail: rosane.lowenthal@gmail.com 